\title{
A Randomized, Placebo-Controlled Study Investigating the Nicotinic $\alpha 7$ Agonist, RG3487, for Cognitive Deficits in Schizophrenia
}

\author{
Daniel Umbricht*,', Richard SE Keefe ${ }^{2}$, Stephen Murray ${ }^{3}$, David A Lowe ${ }^{3,4}$, Richard Porter ${ }^{1,5}$, \\ George Garibaldi' and Luca Santarelli'
}

'CNS Research and Early Development, F. Hoffmann-La Roche, Basel, Switzerland; ²Department of Psychiatry and Behavioral Sciences, Duke University Medical Center, Durham, NC, USA; ${ }^{3}$ Memory Pharmaceuticals, Montvale, NJ, USA

\begin{abstract}
Effective treatments for cognitive impairment associated with schizophrenia (CIAS) remain an unmet need. Nicotinic $\alpha 7$ receptor agonists may be effective in CIAS. This 8-week (week I, inpatient; weeks 2-8, outpatient), double-blind, randomized study used Measurement And Treatment Research to Improve Cognition in Schizophrenia (MATRICS) guidelines to investigate the nicotinic $\alpha 7$ partial agonist RG3487 (formerly MEM3454) in CIAS; 2 I 5 patients with chronic stable schizophrenia received placebo or RG3487 (5, I5, or $50 \mathrm{mg}$ ) added to ongoing treatment with risperidone, paliperidone, or aripiprazole. Primary end point was baseline to week 8 change in MATRICS Consensus Cognitive Battery (MCCB) composite t-score. Secondary outcomes were change in MCCB domain and negative symptom assessment (NSA) scores. The study did not allow for evaluation of nonsmokers. Each RG3487 dose was evaluated using a mixed-effects model repeated measures approach. Mean (SD) baseline MCCB composite t-score was 28.3 (I2.0). No significant effect on MCCB composite $t$-scores was observed with RG3487 (adjusted mean difference (SE) vs placebo: 5 mg: 0.1 I (I.39); I5 mg: - I.95 (1.39); $50 \mathrm{mg}:-1.13$ (1.37); $p=0.2-0.9)$. RG3487 did not improve MCCB domain scores. In a post hoc analysis of patients with moderate negative symptoms, 5 and $50 \mathrm{mg}$ RG3487 vs placebo significantly improved NSA total $(-4.45(p=0.04)$ and -4.75 $(p=0.02)$, respectively) and global $(-0.39(p=0.04)$ and $-0.55(p=0.003)$, respectively) scores. The MCCB did not lead to higher than expected patient withdrawal. RG3487 was generally well tolerated. In patients with stable schizophrenia, RG3487 did not improve cognitive deficits, as assessed by the MCCB; however, in patients with moderate negative symptoms, a post hoc analysis revealed significant improvement of negative symptoms.

Neuropsychopharmacology (20I4) 39, I568-I577; doi:I0.1038/npp.20 I4. I7; published online I9 February 2014
\end{abstract}

Keywords: $\alpha 7$ nicotinic receptor; cognition; randomized controlled study; schizophrenia

\section{INTRODUCTION}

Cognitive impairment is a fundamental characteristic of schizophrenia, and manifests across several domains, including attention, working memory, verbal learning, and problem solving; severity of impairment is a major factor determining functional outcomes (Gray and Roth, 2007).

There is no available cognitive-enhancing treatment and most patients with schizophrenia continue to exhibit

*Correspondence: Dr D Umbricht, Pharmaceutical Division, F. Hoffmann-La Roche, Building 74 3W308, Basel 4070, Switzerland, Tel: +4I 6 I 688 3043, Fax: +4I 6 I 687 9843;

E-mail: daniel.umbricht@roche.com

${ }^{4}$ David A Lowe was an employee of Memory Pharmaceuticals at the time the study was conducted

${ }^{5}$ Richard Porter was an employee of F. Hoffmann-La Roche at the time the study was conducted

Poster presented at the 48th Annual Meeting of the American College of Neuropsychopharmacology, Hollywood, Florida, USA, 6-10 December 2009

Received 29 July 20 I3; revised I 8 December 20 I3; accepted 3 January 2014; accepted article preview online 27 January 2014 pronounced deficits despite positive symptom control with antipsychotic treatment (Gray and Roth, 2007). The Measurement And Treatment Research to Improve Cognition in Schizophrenia (MATRICS) program was set up to tackle this high unmet medical need, and to provide guidance on study design when testing candidate molecules for cognitive impairment associated with schizophrenia (CIAS) (Buchanan et al, 2005; Kern et al, 2008).

Although cholinesterase inhibitors have procognitive efficacy in Alzheimer's disease (AD), they do not appear to offer benefit in CIAS (Singh et al, 2012), which may be attributed to the different pathophysiological mechanisms underlying deficits in CIAS and AD (Wang et al, 2009).

Based on the observation that nicotinic acetylcholine receptors (nAChRs) play an important role in cognitive function, $\alpha 7 \mathrm{nAChRs}$ are key targets for procognitive interventions (Buchanan et al, 2005). For example, in schizophrenia, $\alpha 7 \mathrm{nAChR}$ protein expression is decreased in the hippocampus, thalamus, and frontal and cingulate cortex, with altered transcription seen in post-mortem brain samples (Gotti and Clementi, 2004; Severance and 
Yolken, 2008). However, despite the $\alpha 7 \mathrm{nAChR}$ partial agonist, GTS-21, initially showing cognitive efficacy (Olincy et al, 2006), another study could not confirm this finding (Freedman et al, 2008). In addition, the positive allosteric modulator of the $\alpha 4 \beta 2$ - and $\alpha 7$-nAChRs, galantamine, produced negative procognitive results in patients with schizophrenia, although beneficial effects were observed in certain domains, such as processing speed (Buchanan et al, 2008; Lindenmayer and Khan, 2011). Proof-of-concept studies have reported efficacy data for $\alpha 7 \mathrm{nAChR}$ agonists in CIAS; TC-5619 adjunctive to quetiapine or risperidone improved cognitive functioning in patients with stable schizophrenia at week 12, as measured by the Groton Maze Learning Test (Lieberman et al, 2013). Similarly, EVP-6124 adjunctive to antipsychotic therapy improved CogState testing battery Overall Cognition Index scores at week 12 and a positive trend toward better MATRICS Consensus Cognitive Battery (MCCB) scores was observed (Hilt et al, 2011). Thus, available evidence regarding the clinical utility of $\alpha 7 \mathrm{nAChR}$ agonists for CIAS is inconclusive.

Deficient dopamine transmission in the prefrontal cortex (PFC) underlies, or contributes to, negative and cognitive symptoms. In the midbrain, $40-60 \%$ of neurons express $\alpha 7 \mathrm{nAChRs}$, where dopaminergic cells may be activated via $\alpha 4 \beta 2 \mathrm{nAChRs}$, with $\alpha 7 \mathrm{nAChRs}$ fine-tuning dopamine release following neuronal excitation. Thus, by directly enhancing the excitability of ventral tegmental area neurons, activation of $\alpha 7 \mathrm{nAChRs}$ may improve negative and cognitive symptoms via increased PFC dopamine release (Kucinski et al, 2011). This is the reported rationale for the TC-5619 and EVP-6124 programs; indeed, these agents have reduced negative symptoms in schizophrenia (Lieberman et al, 2013; Hilt et al, 2011). Reductions in negative symptoms with GTS-21, TC-5619 and EVP-6124 support the hypothesis that targeting $\alpha 7 \mathrm{nAChRs}$ may address multiple deficits in schizophrenia (Lieberman et al, 2013; Freedman et al, 2008; Hilt et al, 2011; Kucinski et al, 2011).

The $\alpha 7 \mathrm{nAChR}$ partial agonist, RG3487, was primarily developed to treat cognitive impairment in $\mathrm{AD}$, and demonstrated procognitive effects in animal models of impaired cognition, healthy volunteers $(15,50$, and $150 \mathrm{mg} /$ day), and in a phase IIa study in $\operatorname{AD}(5,15$, and $50 \mathrm{mg} /$ day $)$. However, RG3487 did not improve cognition when added to donepezil in a Phase IIb study in mild-to-moderate $\mathrm{AD}$ (F. Hoffmann-La Roche; data on file (NCT00454870)).

RG3487 was taken into clinical development for CIAS in this 8-week study that was designed using MATRICS guidelines and aimed to provide proof of concept that RG3487 (5, 15, and $50 \mathrm{mg} /$ day), adjunct to selected secondgeneration antipsychotics, is a well-tolerated and effective procognitive treatment for CIAS.

\section{PATIENTS AND METHODS}

\section{Study Design}

This was a multicenter, randomized, double-blind, placebocontrolled, parallel-group, proof-of-concept study conducted in the United States (NCT00604760). Study phases were: screening, $\leqslant 3$ weeks; double-blind treatment, week 1 , patients hospitalized; weeks $2,4,6$, and 8 , outpatient clinics; and single-blind, placebo/treatment discontinuation, 2 weeks (week 10 visit).

The study was designed and implemented, and is reported in accordance with the International Conference on Harmonization Guidelines for Good Clinical Practice, with applicable local regulations, and with the ethical principles in the Declaration of Helsinki. Each Institutional Review Board/Independent Ethics Committee/Research Ethics Board reviewed and approved the protocol and informed consent form.

\section{Participants}

Inclusion criteria. Eligible male or female patients were aged 18-55 years (inclusive) with a schizophrenia diagnosis according to Diagnostic and Statistical Manual of Mental Disorders-IV-TR (American Psychiatric Association, 2000) and established by structured clinical interview, and clinically stable for $\geqslant 12$ weeks, with no evidence of dementia or cognitive decline according to the investigator's clinical judgment.

Patients also had baseline Positive and Negative Symptom Scale (PANSS) total score $\leqslant 70$; PANSS positive symptoms subscore $\leqslant 20$; PANSS Hallucinatory Behavior item score $\leqslant 4 ; \geqslant 1$ month on the same dose of antipsychotic medication; presence of few/no extrapyramidal symptoms (EPS) at baseline (Simpson-Angus Scale (SAS) score $<6$ ); and a negative urine drug screen. Women of childbearing potential were to use two reliable methods of birth control.

Patients had to be able to complete MATRICS testing, be fluent in English, and able to provide informed consent.

Exclusion criteria. Exclusion criteria included: schizophrenia diagnosis within 3 years; current risk of suicide, or history of suicidal behavior within 6 months; hospitalization for psychiatric symptoms within 3 months; diagnosis of any other Axis I disorder; substance abuse/dependence within 6 months; electroconvulsive therapy within 3 months; any history of seizure disorder, migraine headaches requiring prophylaxis treatment, or neurological illness that affects cognitive function or head trauma; any history of stroke or transient ischemic attack; electrocardiogram abnormality at screening; blood pressure or laboratory abnormalities; or any medical condition interfering with participation.

Prior medications. Regular recent treatment with the following medications was not permitted: anticonvulsants/ antiepileptics, mood stabilizers, antipsychotics (except risperidone, aripiprazole, or paliperidone), anticholinergics (unless stable dose for $\geqslant 1$ month before screening and dose expected to continue unchanged during the study, with minimal EPS), 5- $\mathrm{HT}_{3}$ antagonists, nicotine replacement therapy, smoking cessation medications or remedies, or QT-prolonging drugs, or use of other investigational drug within 1 month.

\section{Interventions}

This study investigated RG3487 (Patheon, Toronto, ON, Canada; 5, 15, and $50 \mathrm{mg}$ ), supplied as 5 and $25 \mathrm{mg}$ capsules given adjunctively to ongoing stable antipsychotic 
treatment; placebo capsules were matching in size and color. All doses were derived from three capsules.

Dose selection was based on results of preclinical studies indicating an effective plasma concentration in the range of $5-50 \mathrm{ng} / \mathrm{ml}$, and observed exposures and results in cognitive testing in a multiple ascending dose study in healthy volunteers in which doses up to $150 \mathrm{mg}$ /day were investigated. The chosen doses were expected to lead to exposure covering and exceeding the assumed effective exposure range.

Permitted concomitant medications. Patients were maintained on a fixed dose of preexisting second-generation antipsychotics (risperidone, aripiprazole, or paliperidone), prescribed within guidelines from US package inserts. Selective-serotonin reuptake inhibitors were permitted if the dose was stable for $\geqslant 1$ month before randomization and expected to continue unchanged during the study.

Hypnotics and benzodiazepines at the recommended dose were permitted if: stable, but intermittent, dose for $\geqslant 1$ month; not taken $\leqslant 12 \mathrm{~h}$ before any cognitive assessment; not used $>4$ times in any week.

\section{Randomization and Blinding}

A centralized, randomization schedule was generated, stratified by smoking category so that nonsmoking subjects were equally represented across treatment arms. Smokers were defined as having 15-40 cigarettes/day (inclusive) and cotinine in the blood at screening, nonsmokers were selfreported smoking-free for 3 months and had no cotinine in the blood at screening, and other smokers were those who were neither smokers nor nonsmokers. There were no specific instructions for smokers during the trial.

An Interactive Voice Response System randomly assigned eligible patients to a treatment group in sequential order on day 1 (randomization). Treatment identity remained blinded from randomization until database lock. Unblinding only occurred in the case of patient emergencies and at study end.

\section{Assessments}

Cognitive status was assessed using the MCCB, which provides an overall composite score of cognitive functioning across seven domains: speed of processing, attention/ vigilance, working memory, verbal learning, visual learning, reasoning and problem solving, and social cognition. MCCB was administered at screening, baseline, and weeks 4, 8 (or early termination), and 10 .

The UCSD Performance-Based Skills Assessment (percent-corrected subscales) (Patterson et al, 2001) was used to evaluate functional capacity in five areas of basic living skills at baseline and at weeks 8 and 10. The Personal and Social Performance scale assessed social and occupational functioning at baseline and at weeks 4-10 (Morosini et al, 2000). The word-reading subtest from the Wide Range Achievement Test, a widely used measure of estimated premorbid intelligence, was measured at baseline.

Psychopathology was assessed using the PANSS (total, positive subscale, negative subscale, general psychopathology subscale, negative symptom Marder factor; Marder et al, 1997) at screening, baseline, and weeks $2-10$, and the
Negative Symptom Assessment (NSA (total, global)) at baseline and postdose weeks 1-10. The NSA was added to the protocol as a specific tool to assess negative symptoms in detail. The Montgomery-Åsberg Depression Rating Scale (MADRS) measured severity of depressive symptoms at baseline and at weeks 1 (after dose) and 2-10. The Clinical Global Impression-Severity (CGI-S) and CGI-Improvement (CGI-I) scales were used to support outcome measures (baseline only (CGI-S scale), and weeks 1 (after dose) and 2-10).

Cigarette consumption was measured using the Weekly Smoking Inventory (Memory Pharmaceuticals, Montvale, $\mathrm{NJ}$ ); this self-report scale was completed by the individual and assessed cigarette purchases and use over the past week.

\section{Outcomes}

Primary efficacy end point. The primary efficacy parameter was change from baseline in the overall composite $t$-score of the MCCB at week 8.

Secondary efficacy end points. In addition to measuring change from baseline at week 8 for all efficacy assessments, change from baseline in the overall composite $t$-score of the MCCB was determined at weeks 4 and 10 .

The effects of RG3487 on positive, negative, and affective symptoms of schizophrenia, and on functional capacity and performance, were evaluated.

Safety and tolerability end points. Safety assessments (adverse events (AEs) and serious AEs (SAEs), vital signs, electrocardiogram, and laboratory tests) were conducted at all visits; EPS were assessed using Abnormal Involuntary Movement Scale (AIMS) total score (weeks 8 and 10); and SAS total and Barnes Akathisia Rating Scale (BARS) total and global assessment scores (after dose, weeks 1-10).

\section{Planned Sample Size and Statistical Hypothesis}

Power calculations indicated that $\sim 40$ patients in each group would provide $80 \%$ power to detect a treatment effect size of 0.6 at a two-tailed $\alpha$-level of $5 \%$. To account for a dropout rate of $25 \%$, target was randomization of 212 subjects.

The null hypothesis stated that there would be no difference between each dose of RG3487 and placebo in MCCB composite $t$-scores, and was tested separately for each dose. The MCCB composite score sums and standardizes data from the seven cognitive domains based upon published normative data. Standardized $t$-scores (mean $t=50 ; \mathrm{SD}=10)$ are generated for the overall composite score and for each domain.

The primary end point was analyzed using the Mixedeffect Model Repeated Measures (MMRM), with treatment, assessment visit week, and treatment by week interaction as fixed categorical effects, along with baseline MCCB composite $t$-score and baseline by week interaction as continuous effects. Secondary efficacy variables were analyzed using the MMRM method already described and an ANCOVA model that included baseline as covariate and the main effects of treatment and study center. 
Statistical analyses were performed using SAS (version 8.2 or higher; SAS Institute). Statistical significance was $\leqslant 0.05$, two tailed, and without adjustment for multiple testing.

\section{Analysis Populations}

The safety population included all randomized patients who received $\geqslant 1$ dose of study medication. The intent-to-treat (ITT) population (used for primary and secondary efficacy analyses) comprised all randomized patients who received $\geqslant 1$ dose of study medication, and had baseline and $\geqslant 1$ postbaseline overall MCCB composite score.

The per-protocol (PP) population included those ITT patients who completed 8 weeks of treatment with $80-120 \%$ study medication adherence, did not receive hypnotics/ benzodiazepines $12 \mathrm{~h}$ before assessments, completed all MCCB assessments, and were $\leqslant 60$ years of age.

\section{RESULTS}

\section{Study Population}

Overall, 215 patients were enrolled and randomized at 22 sites; the first patient was randomized on 27 December 2007 and the last patient visit was 5 February 2009; Figure 1 shows patient flow through the study.

Table 1 shows demographic, smoking, and schizophrenia characteristics at baseline, and concomitant schizophrenia medications after study start. Mean (SD) baseline MCCB composite $t$-score was 28.3 (12.0).

Of the 215 randomized patients (safety population), 194 (90.2\%) were included in the ITT population; the majority of exclusions were because of missing postbaseline MCCB overall $t$-scores $(n=20)$. The PP population comprised 140 patients (65.1\%); the most common exclusion reason from this analysis set was missing MCCB assessments $(n=67)$.

\section{Efficacy Results}

Primary efficacy end point. For all doses, MCCB composite $t$-score improved at study end (Figure 2a); however, in the ITT and PP populations, the change with any RG3487 dose did not differ significantly from placebo (Supplementary Table S1).

\section{Secondary efficacy end points}

$M C C B$ domain scores. There was no trend for improved performance with RG3487 versus placebo on any of the seven cognitive domains assessed (Figure $2 \mathrm{~b}$ and Supplementary Table S1).

Effect of nonsmoking status on MCCB. A statistical analysis could not be carried out because of the small number of nonsmokers enrolled (19-26\%). MCCB composite $t$-score and domain score for smokers and nonsmokers are shown in Supplementary Tables S2 and S3.

Negative symptoms. At end point (last assessment during postbaseline treatment period), the adjusted mean (SE) difference in NSA total score (ANCOVA) from placebo for $5 \mathrm{mg}$ RG3487 was -2.16 (1.31), $p=0.1$, and for $50 \mathrm{mg}$

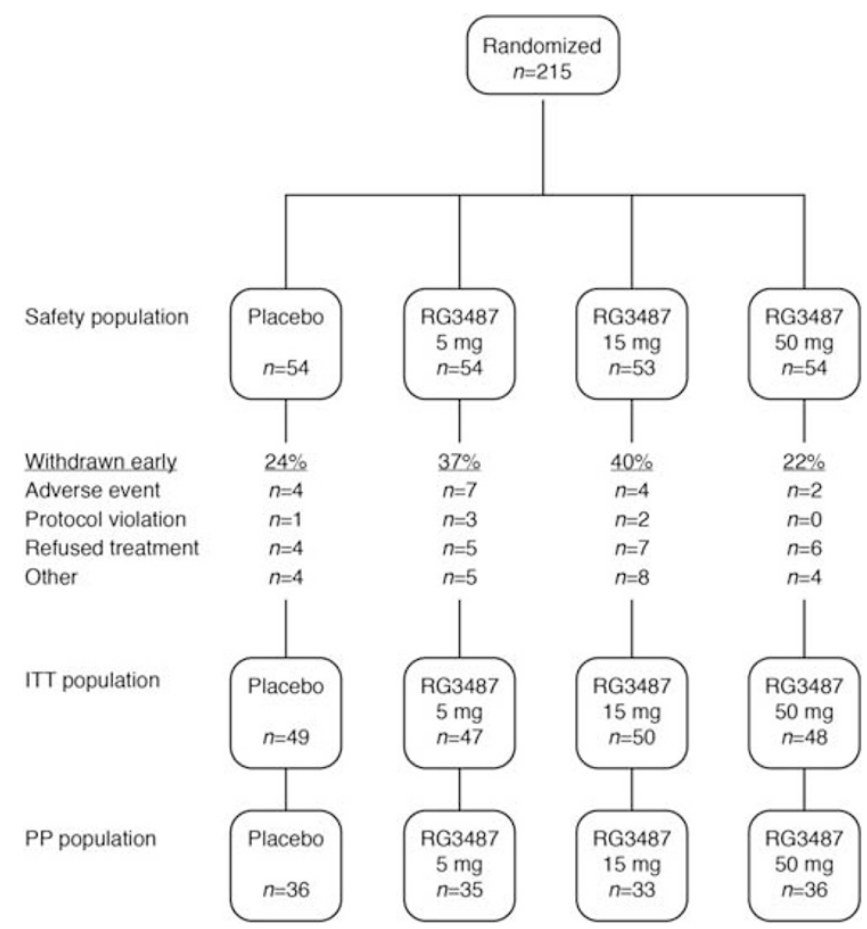

Figure I Participant flow through the study. 'Other' reasons for early withdrawal in $\geqslant 1$ patient included: placebo, 3 patients with two consecutive positive UDSs; 5 mg RG3487, 4 patients lost to follow-up; 15 mg RG3487, 4 patients with two consecutive positive UDSs and 3 patients lost to follow-up; $50 \mathrm{mg}$ RG3487, 2 patients who were lost to follow-up and 2 with two consecutive positive UDSs. Reasons for exclusion from the ITT population were due mainly to not having postbaseline overall MATRICS scores (20 patients), but I patient did not have a baseline MATRICS overall score and I patient (50 mg group) had neither baseline nor postbaseline MATRICS overall scores. Note that patients who withdrew early could still be included in the ITT analysis set. ITT, intent to treat; MATRICS Measurement And Treatment Research to Improve Cognition and Schizophrenia; PP, per protocol; UDS, urine drug screen.

was -2.15 (1.27), $p=0.09$. The $15 \mathrm{mg}$ RG3487 dose did not show a benefit versus placebo $(0.22(1.29), p=0.9)$.

To evaluate effects on negative symptoms further, the sample was divided post hoc into patients with moderately high negative symptoms at baseline (PANSS negative symptom subscale score $>15$ ), and those without negative symptoms, and analyzed based on a MMRM model. Among patients with moderately high negative symptoms, 5 and 50 mg RG3487 significantly improved negative symptoms versus placebo as assessed by the NSA total $(-4.45$ $(p=0.04)$ and $-4.75(p=0.02)$, respectively; Figure 3$)$ and global $(-0.39 \quad(p=0.04)$ and $-0.55 \quad(p=0.003)$, respectively) scale scores.

An inspection of the longitudinal change in NSA scores suggests that only $50 \mathrm{mg}$ RG3487 provided a sustained improvement in negative symptoms from weeks 4 to 8 , whereas $5 \mathrm{mg}$ RG3487 demonstrated no effect at week 4 (Figure 3).

To evaluate whether these effects on negative symptoms were independent of potential changes in positive, depressive, and more general symptoms and level of EPS, we also analyzed in the subgroup of patients with a PANSS negative symptom subscale of $>15$ the changes in scores on the PANSS total scale, the PANSS positive symptom and general 
Table I Patient Demographics, Smoking Status and Smoking Habits, Disease Characteristics and Ongoing Treatment for Schizophrenia at Baseline, and Concomitant Treatment for Schizophrenia Initiated After Study Start (Safety Population)

\begin{tabular}{|c|c|c|c|c|}
\hline & $\begin{array}{l}\text { Placebo, } \\
n=54\end{array}$ & $\begin{array}{c}\text { RG3487 } \\
5 \mathrm{mg}, n=54\end{array}$ & $\begin{array}{l}\text { RG3487 } \\
\text { I } 5 \text { mg, } \\
n=53\end{array}$ & $\begin{array}{c}\text { RG3487 } \\
50 \text { mg, } \\
n=54\end{array}$ \\
\hline \multicolumn{5}{|l|}{ Sex, n (\%) } \\
\hline Female & $14(26)$ & $19(35)$ & $16(30)$ & $17(3 \mid)$ \\
\hline Male & $40(74)$ & $35(65)$ & $37(70)$ & $37(69)$ \\
\hline \multicolumn{5}{|l|}{ Race, n (\%) } \\
\hline African American & $29(54)$ & $36(67)$ & $30(57)$ & $30(56)$ \\
\hline Caucasian & $21(39)$ & $13(24)$ & $20(38)$ & $20(37)$ \\
\hline Other & $4(7)$ & $5(9)$ & $3(5)$ & $4(7)$ \\
\hline Age in years, mean (SD) & $38.1(9.9)$ & $40.1(8.3)$ & $39.6(9.6)$ & $40.5(8.9)$ \\
\hline Range & 19-54 & $20-55$ & $18-55$ & $20-55$ \\
\hline Weight in $\mathrm{kg}$, mean (SD) & $88.4(18.6)$ & $92.8(25.2)$ & $94.0(20.6)$ & $92.3(21.5)$ \\
\hline Range & $52-135$ & $53-164$ & $56-176$ & $54-152$ \\
\hline BMl kg/m², mean (SD) & $29.5(6.5)$ & $30.9(8.6)$ & $32.0(7.4)$ & $31.3(7.6)$ \\
\hline Range & $19-47$ & $18-57$ & $15-56$ & $20-52$ \\
\hline \multicolumn{5}{|l|}{ Smoking status, n (\%) } \\
\hline Smoker & $41(76)$ & $40(74)$ & $41(77)$ & $43(81)$ \\
\hline Nonsmoker & $12(22)$ & $14(26)$ & $12(23)$ & $10(19)$ \\
\hline Other & I (2) & - & - & - \\
\hline $\begin{array}{l}\text { Number of years smoked, } \\
\text { mean (SD) }\end{array}$ & I5.6 (12.0) & $17.5(12.3)$ & $16.3(12.0)$ & $18.6(11.2)$ \\
\hline Range & $0-40$ & $0-41$ & $0-36$ & $0-37$ \\
\hline $\begin{array}{l}\text { Number of cigarettes smoked } \\
\text { per day, mean (SD) }\end{array}$ & $15.3(9.0)$ & |5.| (8.8) & | $4.4(9.0)$ & I5.0 (8.6) \\
\hline Range & $0-40$ & $0-40$ & $0-34$ & $0-40$ \\
\hline PANSS Total Score, mean (SD) & $56.3(10.5)$ & $57.4(10.0)$ & $57.1(10.0)$ & $57.9(10.5)$ \\
\hline Range & $32-70$ & $34-70$ & $34-70$ & $37-70$ \\
\hline NSA Total Score, mean (SD) & $39.7(11.1)$ & $38.6(10.0)$ & $41.6(11.2)$ & $39.2(12.5)$ \\
\hline Range & $20-60$ & $20-62$ & $26-75$ & $17-76$ \\
\hline $\begin{array}{l}\text { MATRICS Overall Composite } \\
\text { t-score, mean (SD) }\end{array}$ & $28.8(12.4)$ & $28.8(13.0)$ & $26.4(11.6)$ & $27.0(10.8)$ \\
\hline Range & $3-55$ & $2-55$ & $7-60$ & $6-48$ \\
\hline $\begin{array}{l}\text { WRAT Reading Test Score, } \\
\text { mean (SD) }\end{array}$ & $52.7(8.3)$ & $56.8(8.0)$ & $53.3(7.8)$ & $54.7(7.5)$ \\
\hline Range & $25-66$ & $36-68$ & $31-69$ & $38-70$ \\
\hline $\begin{array}{l}\text { Antipsychotic treatment, } \\
\mathrm{n}(\%)^{\mathrm{c}}\end{array}$ & $53(98)$ & $49(91)$ & $51(96)$ & $50(93)$ \\
\hline Aripiprazole & $24(44)$ & $15(28)$ & $18(34)$ & $14(26)$ \\
\hline Paliperidone & $10(19)$ & $15(28)$ & $8(15)$ & $8(15)$ \\
\hline Risperidone & $19(35)$ & $19(35)$ & $25(47)$ & $29(54)$ \\
\hline $\begin{array}{l}\text { Concomitant treatment for } \\
\text { schizophrenia (ie, initiated } \\
\text { during the } \\
\text { study), } n(\%)\end{array}$ & $10(19)$ & $9(17)$ & $6(11)$ & $2(4)$ \\
\hline Antidepressant treatment, $n(\%)$ & $3(6)$ & $2(4)$ & 0 & I (2) \\
\hline
\end{tabular}

Abbreviations: BMI, body mass index; MATRICS, Measurement And Treatment Research to Improve Cognition and Schizophrenia; NSA, negative symptom assessment; PANSS, Positive and Negative Symptom Scale; WRAT, Wide Range Achievement Test.

Percentages are based on $n$ (number of valid values).

a Smokers were defined as having 15-40 cigarettes/day (inclusive) and cotinine in the blood at screening; nonsmokers were self-reported smoking-free for 3 months and had an absence of cotinine in the blood at screening; other smokers were those who were neither smokers nor nonsmokers.

${ }^{b}$ Smoking status data for one patient were missing for the RG3487 $50 \mathrm{mg}$ group. ${ }^{c}$ Total patients with $\geqslant 1$ treatment.

subscale, MADRS total and BARS, and AIMS (see Supplementary Table S4). No significant effects were observed for the PANSS total score and the positive subscores. There were effects at trend-level significance on the PANSS general subscores for the 5 and $15 \mathrm{mg}$ groups, but not the $50 \mathrm{mg}$ group. In addition, similar effects were observed for the MADRS total score for the 15 and $50 \mathrm{mg}$ groups. Significant differences were observed for the AIMS total score between placebo and 15 and $50 \mathrm{mg}$; however, they were due to larger changes in the placebo group.

Other secondary efficacy parameters. There was no significant difference between placebo and RG3487 for any of the other secondary efficacy parameters tested (Supplementary Table S5).

Safety and tolerability end points. Overall, $93.8 \%$ of patients received $80-120 \%$ of the expected dose. The frequency and severity of AEs did not appear to differ between RG3487 and placebo, nor was there evidence of a dose-dependent increase in AEs (Table 2). There was no dose-dependent increase in SAEs or in AEs leading to discontinuation, and no indication of abuse liability-related AEs (Table 2). The majority of AEs were mild: $76.4 \%$, placebo; 69.9\%, $5 \mathrm{mg}$ RG3487; 71.9\%, $15 \mathrm{mg}$ RG3487; and $72.6 \%, 50 \mathrm{mg}$ RG3487; 13 were assessed as severe.

Relatively few AEs during the treatment period were assessed by the investigator as 'probably related to treatment' (7.3\%, placebo; 5.8\%, $5 \mathrm{mg}$ RG3487; 3.9\%, 15 mg RG3487; 7.1\%, 50 mg RG3487). Constipation (mainly mild in intensity) was the only AE clearly related to RG3487. Most AEs resolved without sequellae.

Thirteen patients withdrew from treatment because of AEs (Table 2). No patients withdrew from the study because of laboratory abnormalities. Ten patients experienced 13 SAEs (Table 2). One patient receiving $15 \mathrm{mg}$ RG3487 had the dose adjusted after an SAE of suicidal ideation. Seven SAEs led to withdrawal from study treatment; all SAEs, apart from an event of HIV, were resolved without sequellae.

In the $50 \mathrm{mg}$ RG3487 group, 5 patients (10\%) had elevated $\gamma$-glutamyltransferase versus 1,0 , and 1 patient in the placebo, 5, and $15 \mathrm{mg}$ groups, respectively. One subject in the $50 \mathrm{mg}$ group experienced increased serum glutamicpyruvic transaminase, otherwise there was no further evidence of liver involvement.

The frequency of creatine phosphokinase abnormalities was highest with $15 \mathrm{mg}$ RG3487 (28\%) versus $19 \%$, 9\%, and $21 \%$ with placebo, 5 , and $50 \mathrm{mg}$ RG3487, respectively. There were no incidents of marked laboratory abnormalities for renal function or protein measurements.

No abnormal heart rate interval measurements were reported. Overall, QTcF increases $>30-60 \mathrm{~ms}$ were more frequent in patients receiving RG3487 (13\% (5 mg), $15.1 \%$ $(15 \mathrm{mg})$, and $5.6 \%(50 \mathrm{mg}))$ versus placebo (3.7\%). No QTcF increases of $>60 \mathrm{~ms}$ occurred during treatment. There were no notable differences between groups in changes in blood pressure or other vital signs during treatment.

There were no meaningful differences between placebo and RG3487 in change from baseline in AIMS, SAS, and BARS scores.

AEs during the follow-up period. The pattern of AEs following cessation of treatment did not suggest a discontinuation syndrome; overall, 4, 3, 9, and 9 patients 


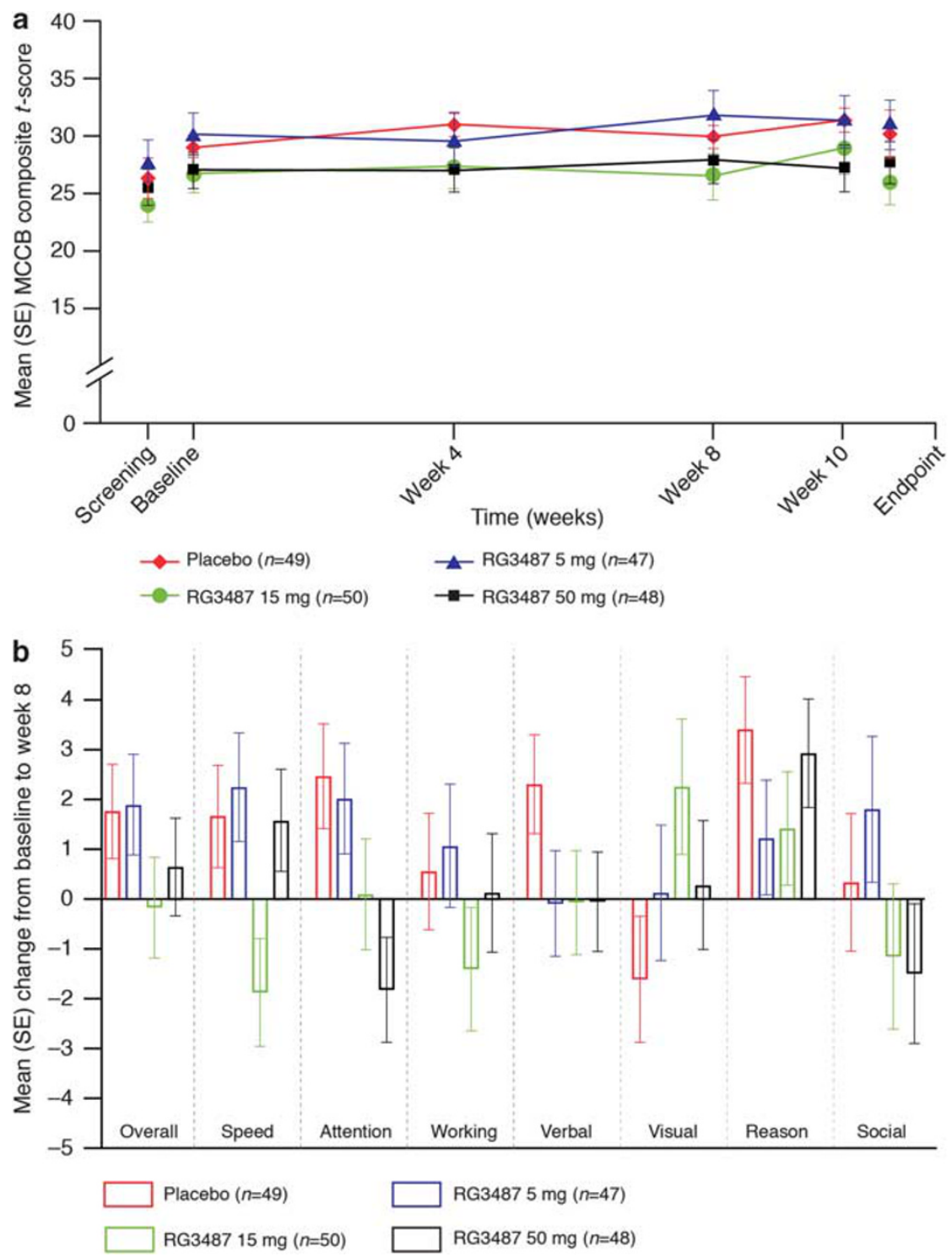

Figure 2 (a) Line plot of mean (SE) MCCB composite t-score over time (MMRM analysis; ITT population). (b) Summary of MCCB overall composite t-score and domain score changes from baseline at week 8 (MMRM analysis; ITT population). Adjusted mean difference (SE) vs placebo: 5 mg: 0.I I (I.39); I5 mg: - I.95 (I.39); $50 \mathrm{mg}:-1.13$ (I.37); p=0.2-0.9. ITT, intent to treat; MCCB, Measurement And Treatment Research to Improve Cognition and Schizophrenia (MATRICS) Consensus Cognitive Battery; MMRM, mixed-effects model repeated measures.

in the placebo and RG3487 5, 15, and $50 \mathrm{mg}$ groups, respectively, reported a total of $5,3,10$, and 10 AEs during the follow-up period.

\section{DISCUSSION}

In this phase IIa, proof-of-concept study, the $\alpha 7 \mathrm{nAChR}$ agonist, RG3487, added to existing antipsychotic therapy did not improve cognitive function versus placebo in patients with chronic schizophrenia, as assessed by the MCCB. In addition, there was no consistent pattern of effects on MCCB domain scores, supporting the outcome of the primary analysis; however, an improvement in negative symptoms was observed in patients with moderately high impairments in this domain at baseline. In general, baseline characteristics were representative of a chronic schizophre- nia population. The mean baseline MCCB scores were almost 2 SDs below the mean (SD) MCCB $t$-score of 50 (10), meaning that this population was highly impaired. However, such a finding is in line with other similar studies (Buchanan et al, 2011; Keefe et al, 2011; Javitt et al, 2012), making this study population highly relevant.

Various factors may have contributed to the negative outcome seen in this study. First, despite the procognitive effects of RG3487 demonstrated in preclinical assays and in healthy volunteers, this agent may not be able to overcome the pathophysiological alteration underlying CIAS, or it is conceivable that $\alpha 7 \mathrm{nAChR}$ agonists are only effective in a subset of patients.

Second, as response to $\alpha 7 \mathrm{nAChR}$ agonist treatment may decline with age (Keefe, 2012), one could speculate that interventions with $\alpha 7 \mathrm{nAChR}$ agonists may yield different 


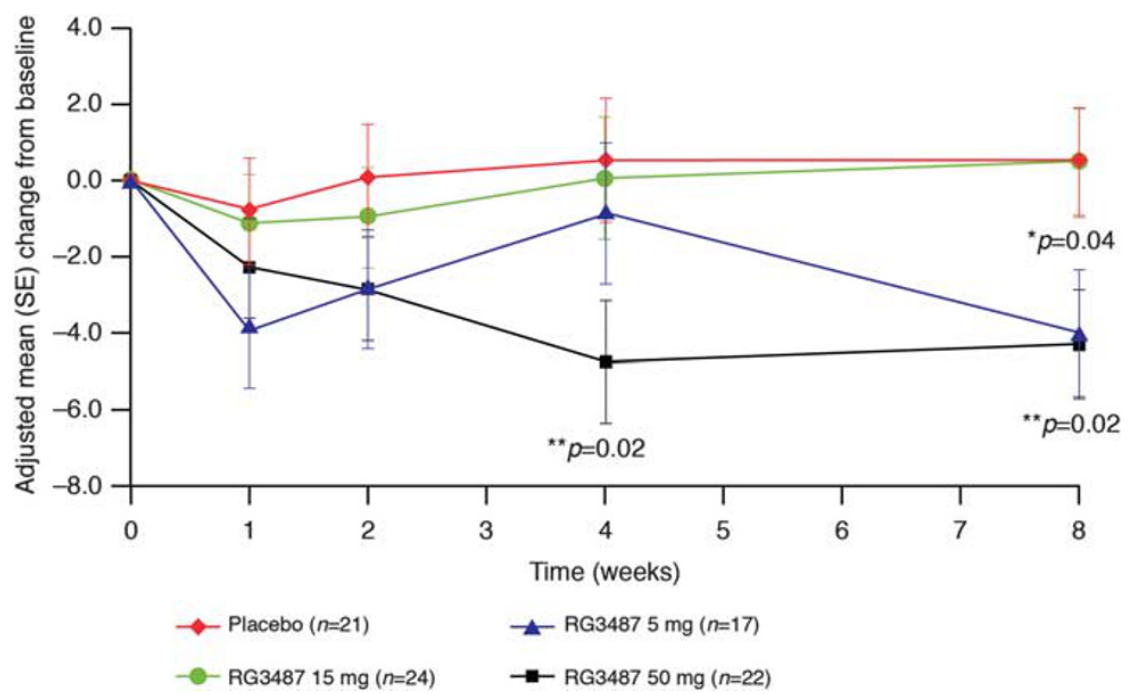

Figure 3 Change from baseline in mean NSA total score over time for patients with a PANSS negative score > I5 at baseline (MMRM analysis; ITT population). ITT, intent to treat; MMRM, mixed-effects model repeated measures; NSA, negative symptom assessment; PANSS, Positive and Negative Symptom Scale. P-values are vs placebo.

results in first-episode or recent-onset schizophrenia versus chronic illness. However, in this data set, there was no indication that RG3487 resulted in different effects in younger patients (data not shown).

Third, a single treatment approach for CIAS may not be sufficient; for example, although an $\alpha 7 \mathrm{nAChR}$ agonist may improve the biochemical milieu in the brain, a wholly successful intervention may also require intense cognitive training to supplement the benefits provided by pharmacotherapy (Genevsky et al, 2010).

Although representative of the smoking habits of patients with schizophrenia, the low number of nonsmokers in this study precluded the possibility of meaningful subgroup analyses. It is hypothesized that administration of nicotine may be an attempt at self-medication in patients with schizophrenia, and that extracting high levels of nicotine could target the lower-affinity, rapidly desensitizing $\alpha 7 n A C h R s$ (Adler et al, 1998). Smoking might affect not only the response of $\alpha 7 \mathrm{nAChRs}$ to acetylcholine, but also to exogenous agonists, masking any potential benefit of these agents in smokers; however, this theory remains unproven.

Practice effects can confound evaluation of agents designed to treat cognitive deficits. In this study, the practice effect can be considered small $(\mathrm{d}=0.3)$; therefore, a clinically meaningful benefit would be greater than such a small practice effect (Kraemer and Kupfer, 2006), particularly as the overall severity of cognitive deficits in the randomized population was greater than 2 SDs, thereby providing sufficient opportunity to observe improvement. These data are consistent with the small practice effects reported in other large multisite clinical trials for which the MCCB was designed (Hilt et al, 2011; Keefe et al, 2013; Keefe et al, 2011).

A further explanation for the outcome of the present study is that RG3487 is not effective in CIAS; nonetheless, as TC-5619 and EVP-6124 each met their primary cognitive end point in phase II studies, $\alpha 7 \mathrm{nAChR}$ agonists may still offer clinical utility in this setting (Lieberman et al, 2013;
Hilt et al, 2011). Limited data are available for the TC-5619 and EVP-6124 phase II studies; both were conducted over 12 weeks, with little benefit reported with TC-5619 by week 8 , suggesting that cognitive efficacy may not be seen with $\alpha 7 \mathrm{nAChR}$ agonists during shorter treatment durations (Lieberman et al, 2013), and thus differences in clinical trial designs may explain the discrepancy in outcomes. In addition, the individual pharmacological profiles of these agents are likely to play a role in the pharmacodynamic effects observed; for example, TC-5619 is a full agonist at the $\alpha 7 \mathrm{nAChR}$, and EVP-6124 and RG3487 are partial agonists at this receptor, with differences in $5-\mathrm{HT}_{3}$ receptor antagonism, a further confounder. Further clinical trial data for TC-5619 and EVP-6124 in CIAS are awaited; however, it is apparent that RG3487 did not improve cognition in our randomized population under these study conditions.

Thus, although preclinical models and other pharmaceutical phase II proof-of-concept trials have demonstrated $\alpha 7 n A C h R$ agonist efficacy, phase III clinical studies are required to show unequivocal cognitive benefit. Nonetheless, there are signals of clinical efficacy on several specific cognitive scales. A number of properties associated with the $\alpha 7 \mathrm{nAChR}$, such as the impact of dosage and dosing schedule on the balance between activation and desensitization of the ion channel, receptor binding affinity, the selection of comedication, and the choice of clinical scales, may confound clinical interpretation of cognitive-enhancing agents that target this receptor (Geerts, 2012).

As this study was not designed to investigate RG3487 efficacy against negative symptoms, low-to-moderate severity was reported at baseline; nonetheless, 5 and $50 \mathrm{mg}$ RG3487 significantly reduced NSA total scores in patients with baseline PANSS scores $>15$, with the $50 \mathrm{mg}$ dose providing a sustained improvement from week 4 . These significant effects were not accompanied by changes in positive symptoms. However, a reduction in depressive symptoms, which were relatively high at baseline indicating mild-to-moderate levels of depression, was observed in the 15 and $50 \mathrm{mg}$ groups. This raises the question of whether 
Table 2 Overview of Adverse Events (Safety Population)

\begin{tabular}{|c|c|c|c|c|}
\hline & $\begin{array}{c}\text { Placebo, } \\
n=54\end{array}$ & $\begin{array}{c}\text { RG3487 } \\
5 \mathrm{mg} \\
n=54\end{array}$ & $\begin{array}{l}\text { RG3487 } \\
\text { I } 5 \mathrm{mg} \\
n=53\end{array}$ & $\begin{array}{c}\text { RG3487 } \\
\mathbf{5 0 ~ m g} \\
n=54\end{array}$ \\
\hline Total $A E s^{\mathrm{a}}$ & $36(67)$ & $38(70)$ & $39(74)$ & $34(63)$ \\
\hline AEs during follow-up & $4(7)$ & $3(6)$ & $9(17)$ & $9(17)$ \\
\hline$S A E S^{a}$ & $2(4)$ & $4(7)$ & $2(4)$ & $2(4)$ \\
\hline Psychiatric disorders & I (2) & $2(4)$ & I (2) & $2(4)$ \\
\hline $\begin{array}{l}\text { Infections and } \\
\text { infestations }\end{array}$ & 0 & $2(4)$ & 0 & 0 \\
\hline $\begin{array}{l}\text { Gastrointestinal } \\
\text { disorders }\end{array}$ & I (2) & 0 & 0 & 0 \\
\hline General disorders & I (2) & 0 & 0 & 0 \\
\hline $\begin{array}{l}\text { Musculoskeletal and } \\
\text { connective tissue } \\
\text { disorders }\end{array}$ & 0 & 0 & I (2) & 0 \\
\hline $\begin{array}{l}\text { AEs leading to study } \\
\text { medication discontinuation }^{\mathrm{a}}\end{array}$ & $3(6)$ & $6(11)$ & $2(4)$ & $2(4)$ \\
\hline Psychiatric disorders & $2(4)$ & $3(6)$ & I (2) & $2(4)$ \\
\hline $\begin{array}{l}\text { Gastrointestinal } \\
\text { disorders }\end{array}$ & I (2) & $2(4)$ & 0 & 0 \\
\hline $\begin{array}{l}\text { Blood and lymphatic } \\
\text { system disorders }\end{array}$ & 0 & I (2) & 0 & 0 \\
\hline Cardiac disorders & 0 & 0 & I (2) & 0 \\
\hline $\begin{array}{l}\text { Infections and } \\
\text { infestations }\end{array}$ & 0 & I (2) & 0 & 0 \\
\hline $\begin{array}{l}\text { Abuse liability-related } \\
\mathrm{AEs}^{\mathrm{a}}\end{array}$ & $18(33)$ & $14(26)$ & $18(34)$ & $9(17)$ \\
\hline \multicolumn{5}{|l|}{ AEs by preferred term ${ }^{\mathrm{a}}$} \\
\hline Headache & $6(11)$ & $6(11)$ & $13(25)$ & $7(13)$ \\
\hline Constipation & I (2) & $8(15)$ & $9(17)$ & II (20) \\
\hline Somnolence & $5(9)$ & $3(6)$ & $4(8)$ & $3(6)$ \\
\hline Dyspepsia & $4(7)$ & $3(6)$ & $3(6)$ & $4(7)$ \\
\hline Insomnia & $5(9)$ & $4(7)$ & $3(6)$ & I (2) \\
\hline Anxiety & $6(11)$ & $2(4)$ & $2(4)$ & I (2) \\
\hline Dizziness & $2(4)$ & $3(6)$ & $4(8)$ & $2(4)$ \\
\hline Toothache & $4(7)$ & I (2) & $5(9)$ & I (2) \\
\hline $\begin{array}{l}\text { Blood creatine } \\
\text { phosphokinase } \\
\text { increased }\end{array}$ & $2(4)$ & I (2) & $3(6)$ & $4(7)$ \\
\hline Nausea & $5(9)$ & $2(4)$ & $3(6)$ & 0 \\
\hline Back pain & $2(4)$ & $3(6)$ & 0 & $2(4)$ \\
\hline Dry mouth & $3(6)$ & $2(4)$ & I (2) & I (2) \\
\hline Agitation & $3(6)$ & I (2) & $2(4)$ & 0 \\
\hline $\begin{array}{l}\text { Upper respiratory tract } \\
\text { infection }\end{array}$ & $2(4)$ & 0 & 0 & $3(6)$ \\
\hline Arthralgia & I (2) & 0 & $3(6)$ & 0 \\
\hline Nasal congestion & $3(6)$ & 0 & 0 & 0 \\
\hline Sinusitis & $3(6)$ & 0 & 0 & 0 \\
\hline
\end{tabular}

Abbreviations: AE, adverse event; MedDRA, Medical Dictionary for Regulatory Activities; SAE, serious adverse event.

Data are $n(\%)$ with percentages based on $n$.

Investigator text for AEs encoded using MedDRA version I0.1.

${ }^{a}$ Total number (\%) of patients with $\geqslant 1$ AEs. Multiple occurrences of the same $A E$ in any one individual were counted only once. the effects on negative symptoms were driven to some extent by changes in depressive symptoms. Alternatively, the MADRS scale may also capture some negative symptoms and thus the observed effects may just reflect changes in negative symptoms. Nonetheless, the results support the hypothesis that agonists at $\alpha 7-\mathrm{nAChR}$ may be an effective treatment against negative symptoms. Studies in carefully selected patients with high negative symptoms but low levels of depression and positive symptoms seem warranted to test this hypothesis further.

In addition to strategies that increase PFC dopamine levels, 5- $\mathrm{HT}_{3}$ receptor antagonism, for example with ondansetron, may be effective against negative symptoms of schizophrenia (Zhang et al, 2006b). GTS-21 (Zhang et al, 2006a), EVP-6214 (Prickaerts et al, 2012), and RG3487 (Wallace et al, 2011) have $5-\mathrm{HT}_{3}$ receptor antagonist properties that may contribute to the effects against this symptom domain observed in this study. As the exact role of $5-\mathrm{HT}_{3}$ receptors in the pathology of schizophrenia symptom domains has not yet been elucidated, any benefit of targeting this receptor remains speculative. Nevertheless, the improvement in negative symptoms observed with RG3487 is in line with those reported with GTS-21, TC-5619, and EVP-6124 (Lieberman et al, 2013; Freedman et al, 2008; Hilt et al, 2011; Kucinski et al, 2011), and suggests that $\alpha 7 \mathrm{nAChR}$ agonists may be effective in the treatment of negative symptoms either via their effect on $\alpha 7 \mathrm{nAChR}$ or currently unknown mechanisms.

Despite some limitations, the study design featured strong methodology, including use of the MCCB that had good test-retest reliability (Keefe et al, 2008; Nuechterlein et al, 2008; Wesnes et al, 2010). Adherence to MATRICS guidelines, which were designed to facilitate the development of new pharmacological treatments for CIAS, is considered a positive feature of this study. In addition, we enrolled a large $(>100)$ patient population representative of chronic schizophrenia, and with a level of cognitive impairment sufficient to allow detection of improvements.

There were no major safety concerns in this study and RG3487 was generally well tolerated, with similar rates and severity of AEs in the placebo and RG3487 groups, and only constipation clearly related to RG3487. There were more study withdrawals from the 5 and $15 \mathrm{mg}$ RG3487 groups than from the placebo and 50 mg RG3487 groups; however, there was no obvious baseline factor or concomitant psychopathology to account for this and no evidence that there was a dose-related incidence of withdrawals because of AEs. There were more discontinuations because of exacerbation of psychosis with RG3487 versus placebo; however, the overall low rate of these SAEs ( $4 \%$ in the 5 and $50 \mathrm{mg}$ and $2 \%$ in the placebo and $15 \mathrm{mg}$ groups) calls their clinical relevance to RG3487 into question.

There was no evidence of abuse liability, and no obvious drug effect on smoking behavior or EPS. Although there was no apparent dose-response pattern, modest QT prolongations $(30-60 \mathrm{~ms})$ were observed more often with RG3487 than with placebo; however, they did not meet the threshold to raise clinical safety concerns.

In summary, the nicotinic $\alpha 7$ partial agonist (and $5-\mathrm{HT}_{3}$ antagonist) RG3487 failed to improve cognitive deficits in patients with chronic stable schizophrenia as assessed by the MCCB. These results do not support the hypothesized 
benefits of this compound on cognitive deficits in schizophrenia. The MCCB was easy to implement and did not did not lead to higher than expected patient withdrawal. Future clinical trials assessing the efficacy of treatments for CIAS may require a design that combines pharmacological intervention with intense cognitive training. Improvements in negative symptoms were observed with RG3487, in line with findings from proof-of-concept studies in schizophrenia with other $\alpha 7 \mathrm{nAChR}$ agonists, suggesting that they may be effective against this domain. The results from phase III studies investigating other $\alpha 7$ nicotinic agonists for CIAS are eagerly awaited to elucidate whether these agents ameliorate cognitive deficits and/or negative symptoms in schizophrenia.

\section{FUNDING AND DISCLOSURE}

Dr Richard Keefe has currently or in the past 3 years received investigator-initiated research funding support from the Department of Veteran's Affair, Feinstein Institute for Medical Research, GlaxoSmithKline, National Institute of Mental Health, Novartis, Psychogenics, Research Foundation for Mental Hygiene, and the Singapore National Medical Research Council. He has currently or in the past 3 years received honoraria, served as a consultant, or advisory board member for Abbvie, Akebia, Amgen, Astellas, Asubio, AviNeuro/ChemRar, BiolineRx, Biomarin, BoehringerIngelheim, Bristol-Myers Squibb, Eli Lilly, EnVivo, Helicon, Lundbeck, Merck, Mitsubishi, Otsuka, Pfizer, Roche, Shire, Sunovion, Takeda, and Targacept. Dr Keefe receives royalties from the BACS testing battery and the MATRICS Battery (BACS Symbol Coding). He is also a shareholder in NeuroCog Trials. David A Lowe was an employee of Memory Pharmaceuticals and received salary, stock options, and support to attend conferences from the company. Daniel Umbricht, George Garibaldi, and Luca Santarelli are employees of F. Hoffmann-La Roche. Richard Porter was an employee of F. Hoffmann-La Roche at the time the study was conducted and is now an employee of Shire Pharmaceuticals. Stephen Murray was a full-time employee of Memory Pharmaceuticals at the time this study was conducted.

\section{ACKNOWLEDGEMENTS}

This study was funded and sponsored by Memory Pharmaceuticals (Montvale, NJ, USA) and the Stanley Medical Research Institute (Chevy Chase, MD, USA), with advice from F. Hoffmann-La Roche (Basel, Switzerland). RG3487 was manufactured by Patheon (Toronto, ON, Canada). Medical writing and editorial support were provided by Watermeadow Medical, Witney, UK, and was funded by F. Hoffmann-La Roche. We thank Dr Kissok Yoo, who was an employee at F. Hoffmann-La Roche when the study was conducted, for technical assistance.

\section{REFERENCES}

Adler LE, Olincy A, Waldo M, Harris JG, Griffith J, Stevens K et al (1998). Schizophrenia, sensory gating, and nicotinic receptors. Schizophr Bull 24: 189-202.
American Psychiatric Association (2000). Diagnostic and Statistical Manual of Mental Disorders. 4th edn text rev. Washington, DC.

Buchanan RW, Conley RR, Dickinson D, Ball MP, Feldman S, Gold JM et al (2008). Galantamine for the treatment of cognitive impairments in people with schizophrenia. Am J Psychiatry 165: 82-89.

Buchanan RW, Davis M, Goff D, Green MF, Keefe RS, Leon AC et al (2005). A summary of the FDA-NIMH-MATRICS workshop on clinical trial design for neurocognitive drugs for schizophrenia. Schizophr Bull 31: 5-19.

Buchanan RW, Keefe RS, Lieberman JA, Barch DM, Csernansky JG, Goff DC et al (2011). A randomized clinical trial of MK-0777 for the treatment of cognitive impairments in people with schizophrenia. Biol Psychiatry 69: 442-449.

Freedman R, Olincy A, Buchanan RW, Harris JG, Gold JM, Johnson L et al (2008). Initial phase 2 trial of a nicotinic agonist in schizophrenia. Am J Psychiatry 165: 1040-1047.

Geerts H (2012). alpha7 Nicotinic receptor modulators for cognitive deficits in schizophrenia and Alzheimer's disease. Expert Opin Investig Drugs 21: 59-65.

Genevsky A, Garrett CT, Alexander PP, Vinogradov S (2010). Cognitive training in schizophrenia: a neuroscience-based approach. Dialogues Clin Neurosci 12: 416-421.

Gotti C, Clementi F (2004). Neuronal nicotinic receptors: from structure to pathology. Prog Neurobiol 74: 363-396.

Gray JA, Roth BL (2007). Molecular targets for treating cognitive dysfunction in schizophrenia. Schizophr Bull 33: 1100-1119.

Hilt D, Meltzer H, Gawry M, Ward S, Dgetluck N, Bhuvaneswaran C et al (2011). EVP-6124, an alpha-7 nicotinic partial agonist, produces positive effects on cognition, clinical function, and negative symptoms in patients with chronic schizophrenia on stable antipsychotic therapy. Abstract accepted for presentation at the 50th Annual Meeting of the American College of Neuropsychopharmacology: Waikoloa, Hawaii, 4-8 December www.acnp.org/annualmeeting/programbooks.aspx.

Javitt DC, Buchanan RW, Keefe RSE, Kern R, McMahon RP, Green MF et al (2012). Effect of the neuroprotective peptide davunetide (AL-108) on cognition and functional capacity in schizophrenia. Schizophr Res 136: 25-31.

Keefe RSE (2012). Issues in the Assessment of Cognition and Functioning in Clinical Trials. ECNP Annual Meeting: Vienna, Austria.

Keefe RS, Buchanan RW, Marder SR, Schooler NR, Dugar A, Zivkov $\mathrm{M}$ et al (2013). Clinical trials of potential cognitiveenhancing drugs in schizophrenia: what have we learned so far? Schizophr Bull 39: 417-435.

Keefe RS, Fox KH, Harvey PD, Cucchiaro J, Siu C, Loebel A (2011). Characteristics of the MATRICS Consensus Cognitive Battery in a 29-site antipsychotic schizophrenia clinical trial. Schizophr Res 125: 161-168.

Keefe RS, Malhotra AK, Meltzer HY, Kane JM, Buchanan RW, Murthy A et al (2008). Efficacy and safety of donepezil in patients with schizophrenia or schizoaffective disorder: significant placebo/practice effects in a 12-week, randomized, double-blind, placebo-controlled trial. Neuropsychopharmaco$\log y$ 33: 1217-1228.

Kern RS, Nuechterlein KH, Green MF, Baade LE, Fenton WS, Gold JM et al (2008). The MATRICS Consensus Cognitive Battery, part 2: co-norming and standardization. Am J Psychiatry 165: 214-220.

Kraemer HC, Kupfer DJ (2006). Size of treatment effects and their importance to clinical research and practice. Biol Psychiatry 59: 990-996.

Kucinski AJ, Stachowiak MK, Wersinger SR, Lippiello PM, Bencherif M (2011). Alpha7 neuronal nicotinic receptors as targets for novel therapies to treat multiple domains of schizophrenia. Curr Pharm Biotechnol 12: 437-448. 
Lieberman JA, Dunbar G, Segreti AC, Girgis RR, Seoane F, Beaver JS et al (2013). A randomized exploratory trial of an alpha-7 nicotinic receptor agonist (TC-5619) for cognitive enhancement in schizophrenia. Neuropsychopharmacology 38: 968-975.

Lindenmayer JP, Khan A (2011). Galantamine augmentation of long-acting injectable risperidone for cognitive impairments in chronic schizophrenia. Schizophr Res 125: 267-277.

Marder SR, Davis JM, Chouinard G (1997). The effects of risperidone on the five dimensions of schizophrenia derived by factor analysis: combined results of the North American trials. J Clin Psychiatry 58: 538-546.

Morosini PL, Magliano L, Brambilla L, Ugolini S, Pioli R (2000). Development, reliability and acceptability of a new version of the DSM-IV Social and Occupational Functioning Assessment Scale (SOFAS) to assess routine social functioning. Acta Psychiatr Scand 101: 323-329.

Nuechterlein KH, Green MF, Kern RS, Baade LE, Barch DM, Cohen JD et al (2008). The MATRICS Consensus Cognitive Battery, part 1: test selection, reliability, and validity. Am J Psychiatry 165: 203-213.

Olincy A, Harris JG, Johnson LL, Pender V, Kongs S, Allensworth $\mathrm{D}$ et al (2006). Proof-of-concept trial of an alpha7 nicotinic agonist in schizophrenia. Arch Gen Psychiatry 63: 630-638.

Patterson TL, Goldman S, McKibbin CL, Hughs T, Jeste DV (2001). UCSD Performance-Based Skills Assessment: development of a new measure of everyday functioning for severely mentally ill adults. Schizophr Bull 27: 235-245.

Prickaerts J, van Goethem NP, Chesworth R, Shapiro G, Boess FG, Methfessel C et al (2012). EVP-6124, a novel and selective alpha7 nicotinic acetylcholine receptor partial agonist, improves memory performance by potentiating the acetylcholine response of alpha7 nicotinic acetylcholine receptors. Neuropharmacology 62: 1099-1110.

Severance EG, Yolken RH (2008). Novel alpha7 nicotinic receptor isoforms and deficient cholinergic transcription in schizophrenia. Genes Brain Behav 7: 37-45.

Singh J, Kour K, Jayaram MB (2012). Acetylcholinesterase inhibitors for schizophrenia. Cochrane Database Syst Rev 1: CD007967.

Wallace TL, Callahan PM, Tehim A, Bertrand D, Tombaugh G, Wang $S$ et al (2011). RG3487, a novel nicotinic alpha7 receptor partial agonist, improves cognition and sensorimotor gating in rodents. J Pharmacol Exp Ther 336: 242-253.

Wang HY, Stucky A, Liu J, Shen C, Trocme-Thibierge C, Morain P (2009). Dissociating beta-amyloid from alpha 7 nicotinic acetylcholine receptor by a novel therapeutic agent, $S$ 24795, normalizes alpha 7 nicotinic acetylcholine and NMDA receptor function in Alzheimer's disease brain. J Neurosci 29: 10961-10973.

Wesnes K, Brooker H, Evins AE (2010). A study comparing the MATRICS battery with the CDR system in schizophrenia. Schizophr Res 117: 416.

Zhang R, White NA, Soti FS, Kem WR, Machu TK (2006a). Nterminal domains in mouse and human 5-hydroxytryptamine $3 \mathrm{~A}$ receptors confer partial agonist and antagonist properties to benzylidene analogs of anabaseine. J Pharmacol Exp Ther 317: 1276-1284.

Zhang ZJ, Kang WH, Li Q, Wang XY, Yao SM, Ma AQ (2006b). Beneficial effects of ondansetron as an adjunct to haloperidol for chronic, treatment-resistant schizophrenia: a double-blind, randomized, placebo-controlled study. Schizophr Res 88: 102-110.

Supplementary Information accompanies the paper on the Neuropsychopharmacology website (http://www.nature.com/npp) 